\title{
Sociodemographic inequities associated with participation in leisure-time physical activity in sub-Saharan Africa: an individual participant data meta-analysis
}

Anna Louise Barr ${ }^{1}$, Uttara Partap ${ }^{1,2}$, Elizabeth H. Young ${ }^{1,2}$, Kokou Agoudavi ${ }^{3}$, Naby Balde ${ }^{4}$, Gibson B. Kagaruki ${ }^{5}$, Mary T. Mayige ${ }^{6}$, Benjamin Longo-Mbenza ${ }^{7,8}$, Gerald Mutungi ${ }^{9}$, Omar Mwalim ${ }^{10}$, Chea S. Wesseh ${ }^{11}$,

Silver K. Bahendeka ${ }^{12,13}$, David Guwatudde ${ }^{14}$, Jutta M. Adelin Jørgensen ${ }^{15}$, Pascal Bovet ${ }^{16,17}$, Ayesha A. Motala ${ }^{18}$ and Manjinder S. Sandhu ${ }^{1 *}$

\begin{abstract}
Background: Leisure-time physical activity (LTPA) is an important contributor to total physical activity and the focus of many interventions promoting activity in high-income populations. Little is known about LTPA in subSaharan Africa (SSA), and with expected declines in physical activity due to rapid urbanisation and lifestyle changes we aimed to assess the sociodemographic differences in the prevalence of LTPA in the adult populations of this region to identify potential barriers for equitable participation.
\end{abstract}

Methods: A two-step individual participant data meta-analysis was conducted using data collected in SSA through 10 population health surveys that included the Global Physical Activity Questionnaire. For each sociodemographic characteristic, the pooled adjusted prevalence and risk ratios (RRs) for participation in LTPA were calculated using the random effects method. Between-study heterogeneity was explored through meta-regression analyses and tests for interaction.

Results: Across the 10 populations ( $N=26,022), 18.9 \%$ (95\%Cl: $\left.14.3,24.1 ; I^{2}=99.0 \%\right)$ of adults ( $\geq 18$ years) participated in LTPA. Men were more likely to participate in LTPA compared with women (RR for women: 0.43; 95\%Cl: $\left.0.32,0.60 ; P<0.001 ; P^{2}=97.5 \%\right)$, while age was inversely associated with participation. Higher levels of education were associated with increased LTPA participation (RR: 1.30; 95\%Cl: $1.09,1.55 ; P=0.004 ; P^{2}=98.1 \%$ ), with those living in rural areas or self-employed less likely to participate in LTPA. These associations remained after adjusting for time spent physically active at work or through active travel.

Conclusions: In these populations, participation in LTPA was low, and strongly associated with sex, age, education, self-employment and urban residence. Identifying the potential barriers that reduce participation in these groups is necessary to enable equitable access to the health and social benefits associated with LTPA.

Keywords: Leisure-time physical activity, Physical activity, Sub-Saharan Africa, Occupational physical activity, Active travel, Global physical activity questionnaire, Recreation, Equity, Urbanisation, Mechanisation

\footnotetext{
* Correspondence: mss31@cam.ac.uk

'Department of Medicine, University of Cambridge, Cambridge, UK

Full list of author information is available at the end of the article
}

\section{$\triangle B M C$}

C C The Author(s). 2020 Open Access This article is licensed under a Creative Commons Attribution 4.0 International License, which permits use, sharing, adaptation, distribution and reproduction in any medium or format, as long as you give appropriate credit to the original author(s) and the source, provide a link to the Creative Commons licence, and indicate if changes were made. The images or other third party material in this article are included in the article's Creative Commons licence, unless indicated otherwise in a credit line to the material. If material is not included in the article's Creative Commons licence and your intended use is not permitted by statutory regulation or exceeds the permitted use, you will need to obtain permission directly from the copyright holder. To view a copy of this licence, visit http://creativecommons.org/licenses/by/4.0/ The Creative Commons Public Domain Dedication waiver (http://creativecommons.org/publicdomain/zero/1.0/) applies to the data made available in this article, unless otherwise stated in a credit line to the data. 


\section{Background}

Physical activity can be undertaken within several domains of an individual's life, with work, travel and leisure-time the most commonly defined. In many highand middle-income countries, increasing mechanisation and the rise in sedentary employment have led to notable declines in the time spent in occupational physical activity $[1,2]$. Likewise, urbanisation and increasing dependence on motor vehicles has led to a reduction in the amount of physical activity accumulated through active travel [3].

Conversely, many of these same countries have observed an increase in the contribution of leisure-time physical activity (LTPA) to total physical activity [1]. Globally, LTPA and its associated market is worth billions, [4] and is an important target for public health interventions attempting to reduce the epidemic of insufficient physical activity amongst populations [5]. Importantly, a number of prospective studies and metaanalyses have indicated that LTPA may have greater health benefits compared with other domains of physical activity [6-8]. However, not all groups are engaged in regular LTPA: women, older adults, and low-income or less educated populations are often less likely to participate $[9,10]$. Many high-income countries (HICs) are working hard to identify and tackle the social, economic and environmental barriers which prevent these groups from participating in regular LTPA, and to ensure equitable access to the associated health and social benefits [11-13].

By contrast, knowledge of the physical activity patterns of populations in sub-Saharan Africa (SSA) is limited. Africa is the fastest urbanising continent, [14] and in recent decades has experienced rapid lifestyle changes, mirroring those observed in higher income countries. A recent review illustrated that for sub-Saharan African countries with lower levels of physical activity, the contribution of occupational physical activity to total physical activity was reduced, while the contribution of active travel increased [15]. The contribution of LTPA was low across all countries [15]. However, this review did not estimate the prevalence of participation across the different domains of physical or assess the differences in participation across population subgroups.

With increasing economic development, the contribution of LTPA to total physical activity is likely to rise in sub-Saharan African populations; however, currently little is known about those participating in LTPA. Using data from 10 diverse populations across SSA, we sought to address the current gap in understanding by assessing the prevalence of participation in LTPA, and the associated sociodemographic factors, to help identify the groups at risk of exclusion and potential barriers to participation within the African context.

\section{Methods}

\section{Survey methods}

As part of the ongoing collaborative work of the African Partnership for Chronic Disease Research, individual participant data (IPD) from 10 large-scale adult population surveys were collated for the purpose of these analyses. These surveys were conducted in nine countries: Democratic Republic of Congo (DRC), [16] Guinea, [17] Kenya, [18] Liberia, [19] Seychelles, [20] South Africa, [21] United Republic of Tanzania (consisting of Tanzania and Zanzibar), [22, 23] Togo, [24] and Uganda [25]. All studies utilised or were consistent with the WHO STEPwise approach to noncommunicable disease risk factor surveillance tool (STEPS), which includes the Global Physical Activity Questionnaire (GPAQ) [26]. The methods of each survey are described in greater detail elsewhere [16, 17, 19-25, 27]. Each study employed a multi-level sampling strategy (Supplementary Table S1), and was designed to be representative of the national or subnational populations from which they were drawn. Surveys were conducted through face-to-face interviews, with all surveys apart from Liberia having responses greater than 70.0\% (Supplementary Table S1).

\section{Definition of exposure and outcomes}

Age, in years, was recoded into six categories: 18-24, $25-34,35-44,45-54,55-64$, and 65 and above. Education was grouped into four categories based on the highest education level completed: primary education not completed, primary education completed, secondary education completed, and tertiary education completed (Supplementary methods). Employment status was recategorised from nine to four categories (Supplementary methods): public or private employees; self-employed; non-income workers; and no occupation. Participants' height and weight measurements were used to calculate their body-mass index (BMI). BMI was categorised into four categories based on standard cut-offs: underweight (BMI: < $18.5 \mathrm{~kg} / \mathrm{m}^{2}$ ); healthy weight (BMI: $18.5-24.9 \mathrm{~kg} /$ $\mathrm{m}^{2}$ ); overweight (BMI: $\left.25.0-29.9 \mathrm{~kg} / \mathrm{m}^{2}\right)$; and obese (BMI: $\geq 30.0 \mathrm{~kg} / \mathrm{m}^{2}$ ). Six studies collected data on urban or rural residence.

Physical activity variables were cleaned according to the GPAQ guidelines [28]. Insufficient physical activity was defined as undertaking less than 600 metabolic equivalent (MET) minutes of physical activity per week, [29] while participation in physical activity was defined as undertaking $>0$ MET-minutes of physical activity per week. Participation in LTPA, occupational physical activity or active travel was defined as undertaking $>0$ METminutes of physical activity within these domains.

\section{Statistical analyses}

We conducted a two-step IPD meta-analysis, analysing each dataset separately to obtain study-level estimates, 
before combining them using random effects models of meta-analysis. Participants were included if individuals were aged 18 years and above and had complete information on sex, age, education, employment, BMI, physical activity and sampling units. All analyses were conducted using Stata/SE 14.2 (StataCorp, Texas).

Adjusted prevalence estimates of the sociodemographic characteristics investigated were calculated for each individual study population using mixed effects Poisson regression models with robust standard errors, adjusted for sex, age and clustering at each level of sampling (Supplementary Table S2). Adjusted prevalence estimates for participation in physical activity within each domain overall, and for each sociodemographic group, were then calculated for each individual study using mixed effects Poisson regression models with robust standard errors, adjusted for sex, age and clustering at each level of sampling. Using the metaprop Stata command, which is specifically designed to pool proportions, pooled adjusted prevalence estimates for sociodemographic characteristics and domain participation were calculated using a random effects model [30]. The metaprop command requires a total for each sub-group $(\mathrm{N})$ and a number of the participants within that sub-group with the condition ( $\mathrm{n})$. The predicted $\mathrm{n}$ was calculated by multiplying the individual country adjusted prevalence estimates against the $\mathrm{N}$ for that study-the total number of participants in each study with complete data. The study-specific confidence intervals were calculated using the exact method [30]. The outcomes were normalised using the Freeman-Tukey double arcsine transformation and the pooled adjusted prevalence estimates were computed using the DerSimonian and Laird method [31]. The confidence intervals of the pooled adjusted prevalence estimates were calculated using the Wald method [30].

Poisson regression models, with robust standard errors, were fitted to obtain study-specific risk ratios (RRs) for participation in each domain of physical activity. Mixed effects accounted for the clustered nature of the data. Fullyadjusted models were adjusted for sex, age, education, employment and BMI. The pooled RRs were calculated for each sociodemographic characteristic using a weighted average of the log-adjusted RR, allowing for random effects using the DerSimonian and Laird method [31].

Sensitivity analyses were conducted to check whether a single study substantially influenced the pooled RRs, by excluding each study from the pooled analyses in turn and comparing results with and without the study in question. In supplementary analyses, we investigated whether adjustment for participation in physical activity at work or through travel, or the volume of physical activity accumulated in each domain, affected observed associations with participation in LTPA.
The $\mathrm{I}^{2}$ statistic was used to assess the heterogeneity between study-specific estimates e.g. pooled adjusted prevalence estimates and RRs [32]. We considered values of $\geq 75 \%$ to indicate high heterogeneity, values $<75$ and $>$ $25 \%$ to indicate moderate heterogeneity and values of $\leq 25 \%$ to indicate low heterogeneity [33]. Effect modification was assessed by stratifying the fully-adjusted model by sex, education and residence location (urban/rural). We also assessed whether there was statistical evidence of interaction between sex and all other covariates, education and all other covariates, and residence location and all other covariates, regarding their association with participation in LTPA. This was done by including an interaction term within the fully-adjusted model and pooling the $\log \mathrm{RR}$ for the interaction term using the method of DerSimonian and Laird described above.

Finally, random effects meta-regression was used to explore the influence of study design and population characteristics, listed in Table 1, on the between-study heterogeneity for the fully-adjusted models. Additionally, as the calculated $P$-values using this method tend to be conservative, we conducted permutation tests based on Monte Carlo simulation, adjusting the $P$-values for multiple-testing [34].

\section{Ethics}

Each primary study obtained ethical approvals in its respective country along with informed consent from participants. This study received ethical approval from the Human Biology Research Ethics Committee at the University of Cambridge, UK (Application No: HBREC.2015.05).

\section{Results}

The studies included in this IPD meta-analysis were undertaken over a period of 10 years and were a mixture of representative surveys from national and subnational populations $(N=26,022)$ (Table 1$)$. The studies were conducted in countries at various stages of economic and urban development [35-38].

Women made up 59.5\% (95\% confidence interval (CI): $56.7,62.3 ; I^{2}=95.3 \%$ ) of the population (Table 2). The majority of individuals were aged between 25 and 44 years. A small proportion of the population was educated to tertiary level and 38.5\% (95\%CI: 27.5, 50.0; $I^{2}=$ 99.7\%) were self-employed. Over one third of the population were classified as overweight or obese. For those studies which reported residence location, the majority of individuals lived in rural areas $(60.8 \%$; $95 \% \mathrm{CI}$ : 48.3 , 72.6; $I^{2}=99.7 \%$ ). The pooled prevalence of insufficient physical activity was $9.5 \%$ (95\%CI: $6.3,13.4 ; I^{2}=99.0 \%$ ); however at least $94.1 \%$ (95\%CI: 91.1, 96.5; $I^{2}=98.8 \%$ ) of the population undertook some form of physical activity per week. Overall, the prevalence of participation in LTPA was $18.9 \%$ (95\%CI: $14.3,24.1 ; I^{2}=99.0 \%$ ) (Table 2). LTPA 
Table 1 Study design and population characteristics of included population health surveys

\begin{tabular}{|c|c|c|c|c|c|c|c|}
\hline Study (reference) & Study period & Geographical scope & $\begin{array}{l}\text { Sample size }{ }^{a} \\
\text { (N) }\end{array}$ & Income group & HDI & GDP per capita (US\$) & Urban population (\%) \\
\hline DRC [13] & 2005 & Subnational & 1502 & Low & 0.364 & 218.5 & 37.5 \\
\hline Guinea [14] & 2009 & Subnational & 2125 & Low & 0.380 & 615.1 & 34.4 \\
\hline Togo [21] & 2010 & National & 2051 & Low & 0.457 & 487.9 & 37.5 \\
\hline Liberia [16] & 2011 & National & 2206 & Low & 0.416 & 379.7 & 48.2 \\
\hline Zanzibar [20] & 2011 & Subnational & 2640 & Low & 0.504 & 733.4 & 28.8 \\
\hline Tanzania [19] & 2012 & National & 5525 & Low & 0.513 & 820.2 & 29.5 \\
\hline Seychelles [17] & 2013 & National & 1232 & Upper-middle & 0.766 & $14,764.9$ & 53.2 \\
\hline South Africa [18] & 2013 & Subnational & 1014 & Upper-middle & 0.660 & 6822.5 & 63.8 \\
\hline Uganda [22] & 2014 & National & 3543 & Low & 0.488 & 702.8 & 15.8 \\
\hline Kenya [15] & 2015 & National & 4184 & Low-middle & 0.555 & 1355.0 & 25.6 \\
\hline
\end{tabular}

DRC Democratic Republic of Congo, Income group World Bank income group, HDI Human Development Index, GDP per capita Global domestic product per capita, Urban population: Percentage of the total population living in urban areas.

World Bank income group, HDI, GDP per capita and urban population data relates to year of study [30-33], Zanzibar taken from data reported for Tanzania in 2011 as no regional specific data was available.

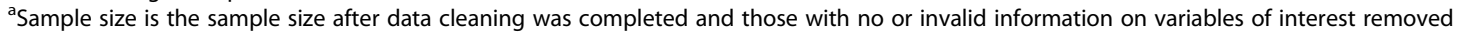

participation ranged from $1.6 \%$ (95\%CI: $0.7,2.4)$ in DRC to $27.1 \%$ (95\%CI: $24.7,29.4$ ) in Tanzania (Supplementary Table S3). By contrast, the pooled adjusted prevalence of participation in physical activity within the domains of work and travel were $70.1 \%$ (95\%CI: $53.5,84.4 ; I^{2}=99.9 \%$ ) and $86.2 \%$ (95\%CI: $\left.82.5,89.5 ; I^{2}=98.5 \%\right)$, respectively (Table 2 and Supplementary Figures S1-S2).

A notably higher proportion of men participated in LTPA compared with women, with participation in LTPA decreasing substantially with age (Fig. 1). We also observed that the proportion of the population participating in LTPA increased with education level. A greater proportion of urban residents reported participating in LTPA compared with rural residents. By contrast, prevalence estimates were generally similar across sociodemographic groups for participation in occupational physical activity or active travel (Supplementary Figures S1-S2 and Supplementary Table S4-S5).

In fully-adjusted Poisson regression analyses, men were more likely to participate in LTPA compared with women (RR for women: 0.43, 95\%CI: 0.32, 0.60; $P<0.001 ; I^{2}=97.5 \% ; P$ for heterogeneity $<0.001$ ) (Fig. 2). Urban residents were more likely to participate in LTPA compared with rural residents (RR for rural: 0.88 ; 95\%CI: $0.80,0.95 ; P=0.005 ; I^{2}=62.1 \%$; $P$ for heterogeneity $=0.022$ ). A strong positive relationship between education and participation in LTPA was observed, while a strong inverse relationship between age and participation in LTPA was also detected. Being self-employed or having no occupation was associated with a notably reduced likelihood of participating in LTPA when compared with those in public or private employment.

By contrast, few sociodemographic characteristics were strongly associated with participation in physical activity at work and through active travel in these populations (Figs. 3 and 4). Education was inversely associated with participation in occupational physical activity. Individuals who were self-employed had a slightly increased likelihood of participating in occupational physical activity when compared with public and private employees, while those with no occupation had a slightly reduced likelihood in participating in physical activity at work or through travel. Unlike LTPA, BMI was inversely associated with reduced participation in physical activity at work and through active travel. Notably, rural residents were more likely to participate in work and travel physical activity compared with urban residents.

Sensitivity analyses revealed no evidence of outlier studies and the interpretation of the RRs for participation in work, travel and leisure-time physical activity remained unchanged regardless of which study was excluded from the pooled analyses (Supplementary Tables S6, S7, S8). Adjusting for participation in occupational physical activity or active travel, or both, did not notably change the RRs for participation in LTPA (Supplementary Figures S3, S4, S5, S6, S7, S8). Likewise, the RRs remained unchanged when total MET-minutes spent in occupational physical activity or active travel, or both, were included in the model (Supplementary Figures S3, S4, S5, S6, S7, S8).

Due to low statistical power $(n=10)$, we were unable to detect substantive evidence that any of the study level or population characteristics listed in Table 1 explained the high levels of between-study heterogeneity observed in these analyses (Supplementary Tables S10, S11, S12).

To further explore the association between sociodemographic characteristics and participation in LTPA, we stratified our models by sex, education and residence location. We observed evidence of a strong interaction between age and sex in the association with LTPA 
Table 2 Pooled adjusted prevalence of sociodemographic characteristics $(N=26,022)$

\begin{tabular}{|c|c|c|c|}
\hline Characteristic & $\mathrm{N}$ & $\%(95 \% \mathrm{Cl})$ & $1^{2}$ \\
\hline \multicolumn{4}{|l|}{$\operatorname{Sex}^{\mathrm{a}}$} \\
\hline Men & 10 & $40.1(37.3,42.9)$ & $95.2 \%$ \\
\hline Women & 10 & $59.5(56.7,62.3)$ & $95.3 \%$ \\
\hline \multicolumn{4}{|c|}{ Age group $^{b}$ (years) } \\
\hline $18-24$ & 9 & $13.0(5.3,23.4)$ & $99.8 \%$ \\
\hline $25-34$ & 10 & $29.9(27.2,32.5)$ & $95.4 \%$ \\
\hline $35-44$ & 10 & $22.4(19.6,25.3)$ & $96.7 \%$ \\
\hline $45-54$ & 10 & $17.0(14.2,20.0)$ & $97.5 \%$ \\
\hline $55-64$ & 10 & $12.1(9.5,15.1)$ & $97.9 \%$ \\
\hline $65+$ & 6 & $2.6(0.6,5.9)$ & 99.29 \\
\hline
\end{tabular}

\section{Education}

Primary education not completed 9

Primary education completed

Secondary education completed

Tertiary education completed

\section{Employment}

Private or public employee

Self-employed

Non-income work

No occupation

\section{BMI $\left(\mathrm{kg} / \mathrm{m}^{2}\right)$}

Underweight

Healthy weight

Overweight

Obese

Residence location ${ }^{c}$

Urban

Rural

\section{Physical activity (MET-mins/wk)}

Insufficient

\section{Participation in physical activity (MET-mins/wk)}

Participation in physical activity (all domains)

Leisure-time physical activity (LTPA)

Occupational physical activity

Active travel
$30.2(19.2,42.4)$

$99.8 \%$

$25.7(15.3,37.9)$

$30.4(17.8,44.6)$

$4.0(2.4,5.9)$

$16.0(9.4,24.0)$

$38.5(27.5,50.0)$

$23.6(16.9,31.0)$

$9.4(4.6,15.7)$

$7.8(5.6,10.3)$

$53.7(47.2,60.2)$

$21.0(17.7,24.4)$

$12.5(8.0,17.8)$

$39.2(27.4,51.7)$

$99.7 \%$

10

$60.8(48.3,72.6)$

$99.7 \%$

$9.5(6.3,13.4)$

$99.0 \%$
$94.1(91.1,96.5)$

$98.8 \%$

$18.9(14.3,24.1) \quad 99.0 \%$

$70.1(53.5,84.4) \quad 99.9 \%$

$86.2(82.5,89.5)$

$\mathrm{N}$ : number of studies; \%: Pooled adjusted prevalence; $95 \% \mathrm{Cl}: 95 \%$ confidence interval; $P^{2}: P^{2}$ statistic indicates proportion of variation due to heterogeneity; METmins/wk: Metabolic Equivalent minutes per week; Insufficient: $<600$ MET-minutes per week; Participation in physical activity: $>0$ MET-minutes of physical activity per week undertaken in all domains; Leisure-time physical activity: $>0$ MET-minutes spent in leisure-time physical activity per week; Occupational physical activity: $>0$ MET-minutes spent in occupational physical activity per week; Active travel: >0 MET-minutes spent in physical activity through active travel per week;

Underweight (BMI: $<18.5 \mathrm{~kg} / \mathrm{m}^{2}$ ); Healthy weight (BMI: $\left.18.5-24.9 \mathrm{~kg} / \mathrm{m}^{2}\right)$; Overweight (BMI: $\left.25.0-29.9 \mathrm{~kg} / \mathrm{m}^{2}\right)$; Obese (BMl: $\geq 30.0 \mathrm{~kg} / \mathrm{m}^{2}$ )

${ }^{\dagger}$ Residence location: $N=20,022$

Adjusted prevalence estimates are based on Poisson regression models adjusted for sex, age and clustering at each level of sampling

${ }^{\mathrm{a} A d j u s t e d ~ p r e v a l e n c e ~ e s t i m a t e s ~ f o r ~ s e x ~ a r e ~ b a s e d ~ o n ~ P o i s s o n ~ r e g r e s s i o n ~ m o d e l s ~ a d j u s t e d ~ f o r ~ a g e ~ a n d ~ c l u s t e r i n g ~ a t ~ e a c h ~ l e v e l ~ o f ~ s a m p l i n g ~}$

${ }^{\mathrm{b}}$ Adjusted prevalence estimates for age group are based on Poisson regression models adjusted for sex and clustering at each level of sampling

'Adjusted prevalence estimates for age group are based on Poisson regression models adjusted for sex and age

Prevalence estimates may not add up to $100 \%$ due to the effects of adjustment 


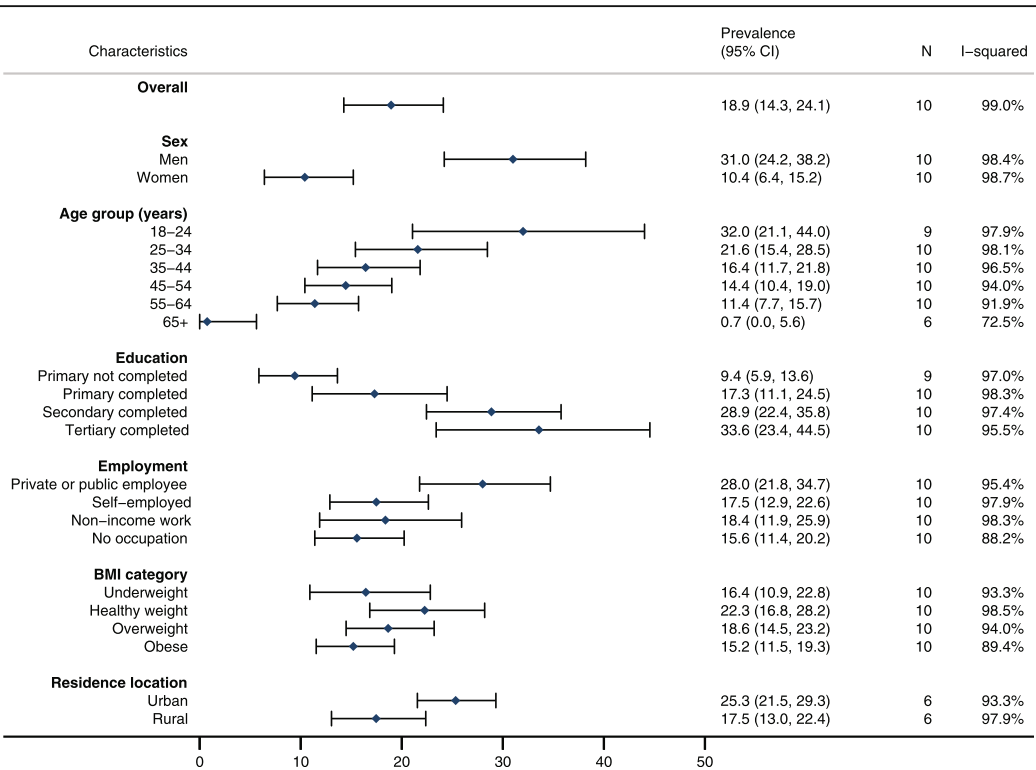

Fig. 1 Pooled adjusted prevalence of participation in leisure-time physical activity $(N=26,022)$. Prevalence: pooled adjusted prevalence; $95 \% \mathrm{Cl}$ : 95\% confidence interval; $\mathrm{N}$ : number of studies; I-squared: $P^{2}$ statistic indicates proportion of variation due to heterogeneity; Underweight (BMI: < $18.5 \mathrm{~kg} / \mathrm{m}^{2}$ ); Healthy weight (BMI: $18.5-24.9 \mathrm{~kg} / \mathrm{m}^{2}$ ); Overweight (BMI: $25.0-29.9 \mathrm{~kg} / \mathrm{m}^{2}$ ); Obese (BMI: $\geq 30.0 \mathrm{~kg} / \mathrm{m}^{2}$ ). Residence location: $N=20,022$. Pooled adjusted prevalence estimates are based on two-step individual pooled data meta-analysis of Poisson regression models adjusted for sex, age and clustering at each level of sampling. Sex: pooled adjusted prevalence estimates for sex are based on two-step individual pooled data meta-analysis of Poisson regression models adjusted for age and clustering at each level of sampling. Age group: pooled adjusted prevalence estimates for age group are based on two-step individual pooled data meta-analysis of Poisson regression models adjusted for sex and clustering at each level of sampling.

participation ( $P$ for interaction $<0.001)$ (Fig. 5). Additionally, rural men were less likely to participate in LTPA compared with urban men; however, no notable differences were observed between urban and rural women. Sensitivity analyses revealed that the RRs for women with no occupation in Guinea strongly influenced the pooled $\mathrm{RR}$, with no notable difference between the sexes observed when Guinea was excluded from the pooled analyses.

We observed no consistent evidence of an interaction between education and all other covariates, or residence location and all other covariates, after sensitivity analyses (Supplementary Figures S9, S10).

\section{Discussion}

Participation in LTPA amongst adults was low in these sub-Saharan African populations when compared with participation in occupational physical activity and active travel. Our findings suggest that women, older adults, lower educated individuals, those who were selfemployed, and rural residents were less likely to participate in LTPA, regardless of the physical activity undertaken in other domains. Few strong sociodemographic associations were observed for participation in occupational physical activity and active travel. With increasing urbanisation and mechanisation, concerted efforts should be made to ensure equitable access to LTPA and the associated health and social benefits.
Due to the multitude of methods for measuring and analysing participation in physical activity across its various domains, direct comparisons with the literature were limited [2, 39-41]. The observed prevalence of LTPA participation was slightly lower than the participation levels reported in the few studies conducted in SSA. Although no time frame was given, $25.4 \%$ of South African adults reported participating in some form of LTPA in a nationally-representative survey [42]. In Nigeria, 26.5\% of a predominantly rural population participated in vigorous LTPA, and $20.4 \%$ participated in moderate LTPA at least once a week [43]. This was considerably lower than reported participation in HICs: on average $40 \%$ of Europeans were estimated to engage in regular LTPA per week [9].

Among the few studies conducted in African populations, evidence of a difference in participation in LTPA between the sexes was mixed [39, 43-45]. However, our findings are consistent with larger, more representative studies conducted in other lowand middle-income countries and HICs which report less participation in LTPA amongst women [46-48]. Possible explanations include constraints associated with women's traditional responsibilities of managing childcare and domestic chores, [49] a lack of interest, [42] and a shortage of safe and accessible opportunities for LTPA [50]. 


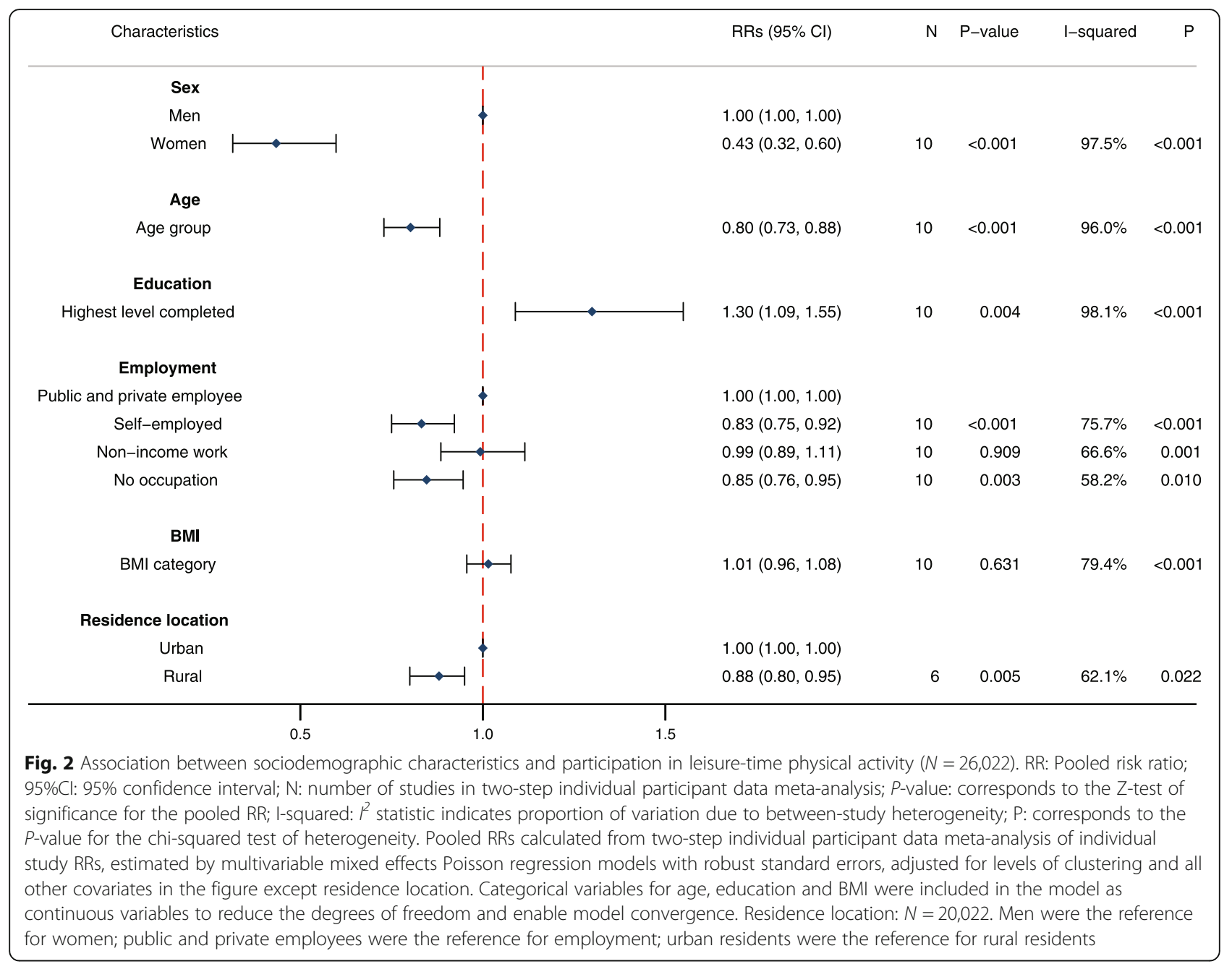

The observed inverse relationship between age and participation in LTPA has previously been reported in African populations and globally [9, 39, 42, 45]. As people retire, and opportunities for physical activity at work or through travel potentially reduce, encouraging participation in LTPA through targeted and accessible programmes for older age groups may help prevent and manage non-communicable diseases (NCDs) and enable opportunities for socialising in a population which is often at risk of isolation.

We observed a strong positive association between education and participation in LTPA. Elsewhere in Africa, increased education has been associated with reduced overall physical activity, [51, 52] with low educational attainment associated with less participation in LTPA in high- and middle-income populations $[9,46]$. Those with higher education may be more aware of the health and social benefits of LTPA and thus motivated to spend their leisure-time physically active, particularly if their work is sedentary [53]. It is also likely that a complex inter-relationship exists between education, employment and socioeconomic status (SES) [53]. Higher levels of educational attainment are likely to increase individuals' opportunities for higher paid employment, reducing the financial constraints which may prevent participation in LTPA. Likewise, these jobs may enable regular participation in LTPA by providing greater flexibility and independence at work [54]. A number of studies globally have observed reduced participation in LTPA amongst those with lower SES [55]. In Kenya, 4.1-6.3\% of individuals living in urban slums engaged in LTPA, compared with the national average of $23.4 \%$ [27, 39, 44]. Time and financial constraints, as well as inaptitude, have been reported as perceived barriers to participation for those with low SES in Botswana, South Africa and other HICs [42, 53, 56].

In these analyses, being self-employed was associated with lower participation in LTPA and increased likelihood of participating in occupational physical activity compared with those in private or public employment. In this context, self-employment is often characterised 


\begin{tabular}{|c|c|c|c|c|c|c|}
\hline Characteristics & & RRs $(95 \% \mathrm{Cl})$ & $\mathrm{N}$ & P-value & I-squared & $P$ \\
\hline \multicolumn{7}{|l|}{ Sex } \\
\hline Men & $\gamma$ & $1.00(1.00,1.00)$ & & & & \\
\hline \multirow[t]{2}{*}{ Women } & $\mapsto \mid$ & $0.97(0.93,1.01)$ & 10 & 0.140 & $91.7 \%$ & $<0.001$ \\
\hline & \multicolumn{5}{|c|}{ Age } & \\
\hline Age group & $10-1$ & $0.98(0.96,1.00)$ & 10 & 0.040 & $96.0 \%$ & $<0.001$ \\
\hline \multicolumn{7}{|l|}{ Education } \\
\hline Highest level completed & $\stackrel{1--11}{\mid}$ & $0.96(0.94,0.98)$ & 10 & 0.001 & $91.4 \%$ & $<0.001$ \\
\hline \multicolumn{7}{|l|}{ Employment } \\
\hline Public and private employee & $\uparrow$ & $1.00(1.00,1.00)$ & & & & \\
\hline Self-employed & $I \longmapsto-1$ & $1.06(1.02,1.11)$ & 10 & 0.005 & $68.1 \%$ & 0.001 \\
\hline Non-income work & $\mapsto H$ & $0.99(0.97,1.02)$ & 10 & 0.697 & $26.0 \%$ & 0.205 \\
\hline No occupation & $\mapsto \quad$ & $0.89(0.85,0.94)$ & 10 & $<0.001$ & $54.1 \%$ & 0.021 \\
\hline BMI & I & & & & & \\
\hline BMI category & $|+| \mid$ & $0.97(0.96,0.99)$ & 10 & 0.001 & $68.7 \%$ & 0.001 \\
\hline Residence location & 1 & & & & & \\
\hline Urban & $\phi$ & $1.00(1.00,1.00)$ & & & & \\
\hline Rural & $\longmapsto$ & - $1.23(1.09,1.39)$ & 6 & 0.001 & $93.3 \%$ & $<0.001$ \\
\hline $\begin{array}{c}1 \\
0.6\end{array}$ & $\begin{array}{c}7 \\
1.0\end{array}$ & $\begin{array}{c}T \\
1.4\end{array}$ & & & & \\
\hline $\begin{array}{l}\text { Fig. } 3 \text { Association between s } \\
95 \% \text { Cl: } 95 \% \text { confidence interv } \\
\text { significance for the pooled RR } \\
\text { P-value for the chi-squared te } \\
\text { study RRs, estimated by multi } \\
\text { other covariates in the figure } \\
\text { continuous variables to reduc } \\
\text { for women; public and privat }\end{array}$ & $\begin{array}{l}\text { hic characteristics and } \\
\text { of studies in two-step i } \\
\text { statistic indicates propc } \\
\text { neity. Pooled RRs calcu } \\
\text { effects Poisson regres } \\
\text { nce location. Categorica } \\
\text { of freedom and enable } \\
\text { vere the reference for e }\end{array}$ & $\begin{array}{l}\text { cupational physic } \\
\text { ant data meta-anal } \\
\text { due to between-s } \\
\text { ep individual partic } \\
\text { robust standard er } \\
\text {, education and B } \\
\text { nce. Residence loc } \\
\text { n residents were tl }\end{array}$ & $\begin{array}{l}\text { ity }(N \\
\text { value: } \\
\text { eteros } \\
\text { data } r \\
\text { djuste } \\
\text { e incl } \\
N=2 \\
\text { rence }\end{array}$ & $\begin{array}{l}=26,022) \text {. } \\
\text { correspor } \\
\text { yeneity; } P \text { : } \\
\text { neta-analy } \\
\text { d for level } \\
\text { uded in th } \\
\text { D,022. Mer } \\
\text { for rural } r\end{array}$ & $\begin{array}{l}\text { Pooled ris } \\
\text { to the Z-t } \\
\text { responds } \\
\text { of individu } \\
\text { clustering } \\
\text { nodel as } \\
\text { ere the ref } \\
\text { dents }\end{array}$ & $\begin{array}{l}\text { k ratio; } \\
\text { est of } \\
\text { o the } \\
\text { al } \\
\text { and all } \\
\text { erence }\end{array}$ \\
\hline
\end{tabular}

by low earnings and informal wages, with a high proportion involved in agricultural work [57]. This is consistent with findings from previous studies which observed that those in higher status occupations had higher levels of LTPA and lower levels of occupational physical activity compared with those in lower status occupations [54].

Rural participation in LTPA was notably lower compared with urban populations, while work and travel physical activity were notably higher, reflecting potential time and energy constraints on individuals. Rural populations are more likely to be involved in time-consuming agricultural work, which often requires high levels of energy expenditure, [52] thus these groups may not have the time or desire to participate in further physical activity during their limited leisure-time [42]. However, in these analyses RRs for participation in LTPA were not notably different after adjustment for participation and time spent physically active during work and travel. Thus, other factors may be associated with lower LTPA participation in rural populations, including fewer opportunities, especially in sparsely populated areas [58].
With increasing mechanisation, particularly in the agricultural sector, these individuals may be at risk of reduced occupational physical activity. Opportunities for LTPA should be available in order to maintain or increase physical activity levels in these populations.

BMI was inversely associated with participation in physical activity at work and through travel but no association was observed with LTPA in these populations. In many HICs, reductions in occupational physical activity have been associated with decreases in energy expenditure [2]. There is also evidence that although LTPA has increased, it has not been to sufficient levels to compensate for the reduction in occupational physical activity and consequently total physical activity has decreased markedly [59]. This is likely to have had an impact on weight maintenance and the risk of NCDs in these populations [60-62]. While there are likely to be other factors involved, relating to economic development and associated lifestyle changes including diet, $[60,62]$ creating opportunities to access the additional health and social benefits of LTPA and to compensate for reductions 


\begin{tabular}{|c|c|c|c|c|c|c|}
\hline Characteristics & & RRs $(95 \% \mathrm{Cl})$ & $\mathrm{N}$ & P-value & I-squared & $P$ \\
\hline \multicolumn{7}{|l|}{ Sex } \\
\hline Men & $\varphi$ & $1.00(1.00,1.00)$ & & & & \\
\hline Women & $\mapsto-1$ & $0.98(0.96,1.01)$ & 10 & 0.140 & $94.9 \%$ & $<0.001$ \\
\hline \multicolumn{7}{|l|}{ Age } \\
\hline Age group & 少 & $0.99(0.99,1.00)$ & 10 & $<0.001$ & $0.0 \%$ & 0.749 \\
\hline \multicolumn{7}{|l|}{ Education } \\
\hline \multirow[t]{2}{*}{ Highest level completed } & $1-0+1$ & $0.99(0.97,1.01)$ & 10 & 0.267 & $90.4 \%$ & $<0.001$ \\
\hline & | & & & & & \\
\hline \multicolumn{7}{|l|}{ Employment } \\
\hline Public and private employee & 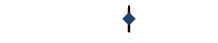 & $1.00(1.00,1.00)$ & & & & \\
\hline Self-employed & $H \cdot-1$ & $1.02(0.99,1.05)$ & 10 & 0.153 & $63.2 \%$ & 0.004 \\
\hline Non-income work & $\longmapsto$ & $0.99(0.94,1.05)$ & 10 & 0.860 & $87.5 \%$ & $<0.001$ \\
\hline No occupation & $\mapsto-1$ & $0.91(0.87,0.96)$ & 10 & $<0.001$ & $81.7 \%$ & $<0.001$ \\
\hline BMI & 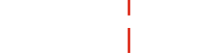 & & & & & \\
\hline BMI category & $\mid-11$ & $0.97(0.96,0.99)$ & 10 & $<0.001$ & $37.4 \%$ & 0.110 \\
\hline \multicolumn{7}{|l|}{ Residence location } \\
\hline Urban & $\varphi$ & $1.00(1.00,1.00)$ & & & & \\
\hline Rural & $\mapsto \bullet-1$ & $1.06(1.03,1.09)$ & 6 & $<0.001$ & $76.1 \%$ & 0.001 \\
\hline 1 & 10 & 1 & & & & \\
\hline $\begin{array}{l}\text { Fig. } 4 \text { Association between } \\
\text { confidence interval; N: numb } \\
\text { for the pooled RR; I-squared: } \\
\text { the chi-squared test of heter } \\
\text { estimated by multivariable } \mathrm{m} \\
\text { covariates in the figure excep } \\
\text { variables to reduce the degre } \\
\text { public and private employee }\end{array}$ & $\begin{array}{l}\text { ic characteristics an } \\
\text { wo-step individual } \\
\text { tes proportion of va } \\
\text { RRs calculated fron } \\
\text { son regression mod } \\
\text { tion. Categorical var } \\
\text { ind enable model cc } \\
\text { ence for employmer }\end{array}$ & $\begin{array}{l}\text { active travel ( } N=26 \\
\text { eta-analysis; P-value } \\
\text { ween-study heteror } \\
\text { ual participant data } \\
\text { andard errors, adjus } \\
\text { acation and BMI we } \\
\text { ence location: } N=2 \\
\text { were the reference }\end{array}$ & $\begin{array}{l}\text { R: Po } \\
\text { pono } \\
\text { P: cc } \\
\text { analys } \\
\text { level } \\
\text { uded } \\
\text { Men } \\
\text { al res }\end{array}$ & $\begin{array}{l}\text { oled risk r } \\
\text { is to the Z } \\
\text { rresponds } \\
\text { is of indiv } \\
\text { of cluster } \\
\text { in the mo } \\
\text { were the r } \\
\text { idents }\end{array}$ & $\begin{array}{l}\text {; } 95 \% \mathrm{Cl}: 9 \\
\text { st of signif } \\
\text { the } P \text {-valt } \\
\text { al study R } \\
y \text { and all o } \\
\text { as contin } \\
\text { rence for }\end{array}$ & $\begin{array}{l}\% \\
\text { cance } \\
\text { e for } \\
\text { s, } \\
\text { eer } \\
\text { ous } \\
\text { omen; }\end{array}$ \\
\hline
\end{tabular}

in occupational physical activity is undoubtedly an important consideration for public health officials in SSA, where the prevalence of overweight and obesity is already high [6-8, 63, 64].

To our knowledge this is the first meta-analysis using IPD from SSA to investigate participation within the three main domains of physical activity. Each study employed sampling strategies which aimed to recruit a representative sample of the national or subnational population from which they were drawn. The overall participant response was relatively high across studies. The studies included in these analyses all utilised or were consistent with the WHO STEPwise approach to non-communicable disease risk factor surveillance tool, a well-established survey tool for population surveillance which has been used in over 122 countries, [65] enabling the standardised collection of key variables. Data were collected by trained interviewers, with BMI objectively measured. Furthermore, identical methods were used to clean and analyse these data, enabling comparability of country- specific estimates and the calculation of more robust pooled estimates.

Self-report questionnaires are currently the main way to measure the domains of physical activity. While the reliability of the GPAQ is high, the validity tends to be low to moderate [66, 67]. However, the outcome of interest for validity studies tends to be volume of physical activity rather than domain, thus it is likely the validity of the GPAQ to measure domain participation is higher as participants are more likely to remember participating in physical activity within a certain domain than the exact time and intensity $[66,67]$.

While the studies included in these analyses aimed to be representative of their national or subnational populations, these findings may not be generalisable to other African populations or reflect the current situation for the populations of older studies. The small number of studies included in these analyses also limited the power to detect sources of heterogeneity at the study level. Due to the cross-sectional nature of these data the temporality of associations and seasonal variations of participation could 


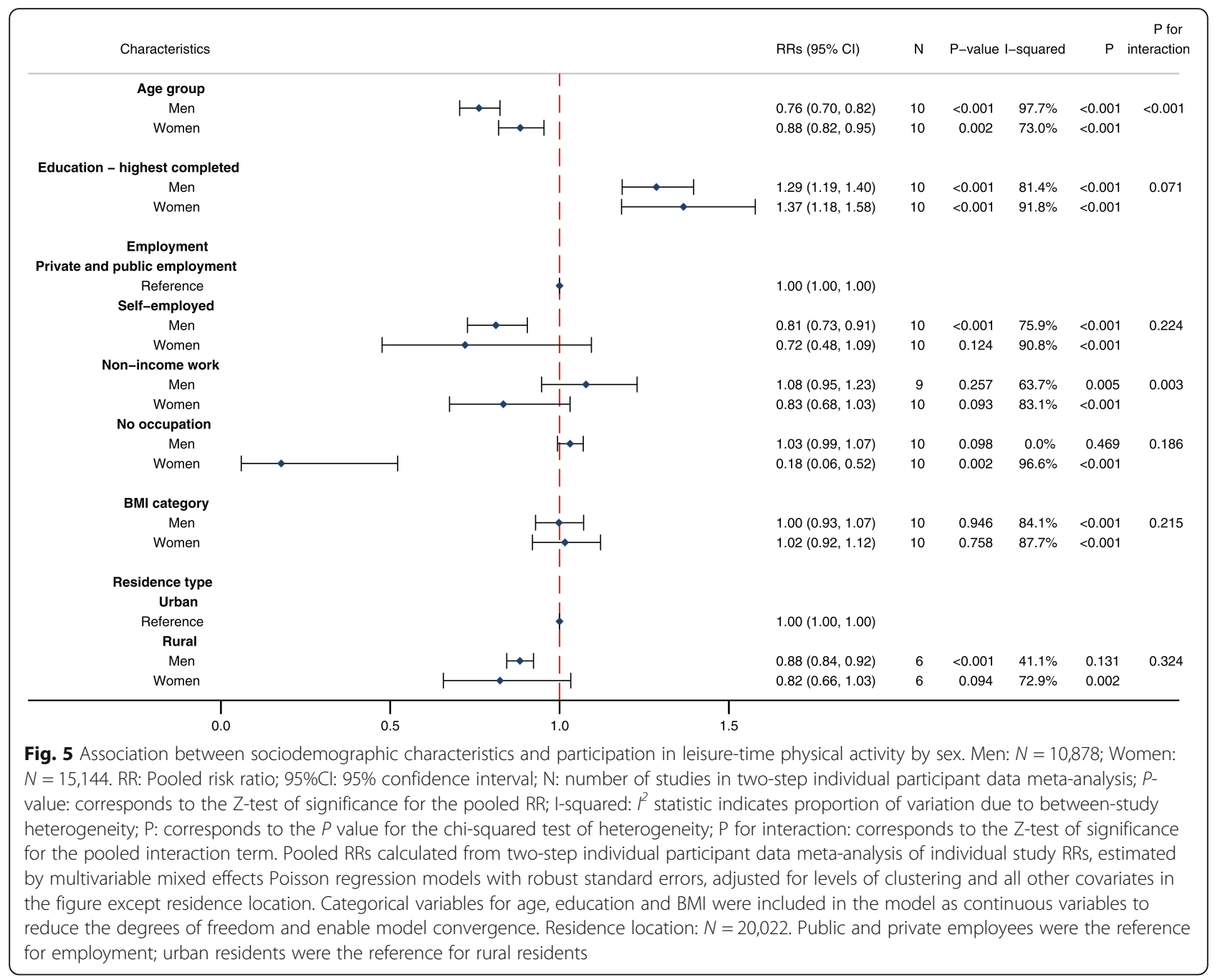

not be assessed. Finally, there is the potential for residual confounding due to unaccounted for confounders.

In 2017, 60\% of African countries had an operational policy or strategy which addressed physical activity, with limited evidence of their effectiveness [68]. To maintain or increase population physical activity levels it will be important for governments and health officials to identify the barriers and motivations associated with participation in LTPA, particularly amongst those groups where participation is notably lower. Providing free recreational facilities will not automatically increase participation, as observed in Kenya [44]: instead a whole system approach is required [5]. Mass media campaigns, such as 'This Girl Can' in the UK and 'Kau Mai Tonga' in Tonga, have shown success in empowering women to engage in physical activity $[11,69,70]$. Such campaigns are a recommended NCD 'Best Buy' and can help shift social norms and perceived barriers to participation if designed appropriately for the African context [71]. Likewise, improving access to opportunities for physical activity throughout life will be critical to ensuring that participation in LTPA does not decline with age. Exposure to physical activity in school was an important motivator for adult women who participated in LTPA in South Africa [42]. Furthermore, positive experiences of physical activity at school and in other settings is important for building individual's confidence to participate $[11,53]$. Along with the health benefits, the opportunity to socialise through LTPA was a key motivator for older people in South Africa [42]. Tailoring physical activity programmes to meet the diverse needs and motivations of groups who are currently at risk of lower participation in LTPA will be important for encouraging and maintaining participation [5]. Likewise, investing in accessible and safe environments for physical activity will be critical for achieving equitable participation in LTPA [50, 72-74].

Furthermore, concerted efforts are needed to strengthen the surveillance infrastructure within SSA to collect longitudinal data on the physical activity patterns 
of these populations, ideally using objective measurement tools supplemented with diaries, to capture the domain in which physical activity is undertaken $[75,76]$. This is important as recent studies suggest differential health benefits across physical activity domains [6-8]. Additionally, high levels of occupational physical activity have been associated with increased risk of all-cause mortality and cardiovascular events, particularly in men, $[7,77]$ with one study reporting that LTPA may modify these associations [78]. However, further studies are needed to understand the specific mechanisms by which these associations may be explained and to better account for residual confounding [75, 79]. Considering the high levels of occupational physical activity, the low participation in LTPA, and the increasing burden of NCDs among populations in SSA, these associations should be of particular interest to governments; however, without prospective research, associations between domains of physical activity and health outcomes cannot be explored. Finally, such surveillance platforms would enable the monitoring of trends and the evaluation of interventions to more clearly establish their effectiveness and inform scale-up strategies [79].

\section{Conclusions}

This study adds to the limited evidence on LTPA participation amongst adults in SSA. We show that participation in LTPA is low in these populations, with women, older adults, less educated, self-employed and rural populations less likely to participate in LTPA. Further research is necessary to understand the personal, social and environmental barriers and motivators for participation in LTPA in these groups. Likewise, investment in surveillance infrastructure will allow us to track temporal trends in domain participation and improve the evidence base for policy development. Finally, as increasing urbanisation and mechanisation leads to declines in population physical activity levels, political and financial commitment from governments is necessary to ensure that the health and social benefits of LTPA are accessible to all [80].

\section{Supplementary information}

Supplementary information accompanies this paper at https://doi.org/10. 1186/s12889-020-08987-w.

\section{Additional file 1.}

\section{Abbreviations}

BMl: Body-mass index; DRC: Democratic Republic of Congo; WHO: World Health Organization; STEPS: WHO STEPwise approach to non-communicable disease risk factor surveillance tool; GPAQ: Global Physical Activity Questionnaire; HICs: High-income countries; IPD: Individual participant data; LTPA: Leisure-time physical activity; SSA: Sub-Saharan Africa; RR: Risk ratio; MET: Metabolic equivalent; NCD: Non-communicable disease; SES: Socioeconomic status

\section{Acknowledgments}

We would like to thank the surveys team who contributed to data collection in the primary studies. We are also grateful to all participants for their involvement in the original surveys.

\section{Authors' contributions}

ALB and MSS conceived the idea for the manuscript. KA, NB, GBK, MTM, BLM, GM, OM, CSW, SKB, DG, JJ, PB, AAM, EHY and MSS provided individual participant data for analyses. ALB cleaned and analysed the data and was the major contributor in writing the manuscript. All authors were involved in the interpretation of the analyses, and read and approved the final manuscript.

\section{Funding}

This work was supported by the African Partnership for Chronic Disease Research strategic award from United Kingdom Medical Research Council (grant number MR/K013491/1); the Wellcome Trust (WT206194); and the National Institute for Health Research Cambridge Biomedical Research Centre (UK). The funders had no role in the study design, data collection, analysis, decision to publish, or preparation of this manuscript.

\section{Availability of data and materials}

The data that support the findings of this study are available from the corresponding author upon reasonable request.

\section{Ethics approval and consent to participate}

Each primary study obtained ethical approvals in its respective country along with informed consent from participants. Following the WHO STEPwise approach to surveillance instrument, a consent form was read to each respondent and verbal consent was provided prior to the survey interview and collection of physical measurements for the Liberia STEPS survey, this was approved by University of Liberia's Research Ethics Committee (University of Liberia Pacific Institute for Research and Evaluation). Written consent was provided by participants for all other studies included. This study received ethical approval from the Human Biology Research Ethics Committee at the University of Cambridge, UK (Application No: HBREC.2015.05).

\section{Consent for publication}

Not applicable.

\section{Competing interests}

The authors declare that they have no competing interests.

\section{Author details}

'Department of Medicine, University of Cambridge, Cambridge, UK. ${ }^{2}$ Wellcome Sanger Institute, Genome Campus, Hinxton, UK. ${ }^{3}$ Togo Ministry of Health, Lome, Togo. ${ }^{4}$ Department of Endocrinology and Diabetes, Donka University Hospital, Conakry, Guinea. ${ }^{5}$ National Institute for Medical Research, Tukuyu Research Centre, Tukuyu, Tanzania. ${ }^{6}$ National Institute for Medical Research, Headquarter Research Centre, Dar es Salaam, Tanzania. ${ }^{7}$ Faculty of Health Sciences, Walter Sisulu University, Mthatha, Eastern Cape, South Africa. ${ }^{8}$ LOMO University of Research, Kinshasa, Democratic Republic of Congo. ${ }^{9} \mathrm{C}$ ontrol of Non-Communicable Diseases Desk, Ministry of Health, Kampala, Uganda. ${ }^{10}$ Zanzibar Ministry of Health, Mnazi Mmoja, Tanzania. ${ }^{11}$ Ministry of Health, Monrovia, Liberia. ${ }^{12}$ Mother Kevin Postgraduate Medical School (MKPGMS), Uganda Martyrs University, Kampala, Uganda. ${ }^{13}$ St. Francis Hospital, Nsambya, Kampala, Uganda. ${ }^{14}$ Department of Epidemiology and Biostatistics, School of Public Health, Makerere University, Kampala, Uganda. ${ }^{15}$ Department of Public Health, University of Copenhagen, Copenhagen, Denmark. ${ }^{16}$ University Center for Primary Care and Public Health (Unisanté), Lausanne, Switzerland. ${ }^{17}$ Ministry of Health, Victoria, Republic of Seychelles. ${ }^{18}$ Department of Diabetes and Endocrinology, Nelson R. Mandela School of Medicine, University of KwaZulu-Natal, Durban, South Africa.

Received: 6 February 2020 Accepted: 24 May 2020

Published online: 15 June 2020

References

1. Knuth $A G$, Hallal PC. Temporal trends in physical activity: a systematic review. J Phys Act Health. 2009;6(5):548-59. 
2. Ng SW, Popkin BM. Time use and physical activity: a shift away from movement across the globe. Obesity Rev. 2012;13(8):659-80.

3. Shoham DA, Dugas $L R$, Bovet $P$, Forrester $T E$, Lambert EV, Plange-Rhule J, et al. Association of car ownership and physical activity across the spectrum of human development: modeling the epidemiologic transition study (METS). BMC Public Health. 2015;15:173.

4. Gera J, Jain S, Gupta S, Sethi S, D'silva S, Munshi A, et al. The business of sports: playing to win as the game unfurls. India: KPMG; 2016.

5. ACTIVE. A technical package for increasing physical activity. Geneva: World Health Organization; 2018.

6. Besson $\mathrm{H}$, Ekelund $\mathrm{U}$, Brage $\mathrm{S}$, Luben R, Bingham S, Khaw KT, et al. Relationship between subdomains of total physical activity and mortality. Med Sci Sports Exerc. 2008;40(11):1909-15.

7. Li J, Loerbroks A, Angerer P. Physical activity and risk of cardiovascular disease: what does the new epidemiological evidence show? Curr Opin Cardiol. 2013;28(5):575-83.

8. Hu G, Sarti C, Jousilahti P, Silventoinen K, Barengo NC, Tuomilehto J. Leisure time, occupational, and commuting physical activity and the risk of stroke. Stroke. 2005;36(9):1994-9.

9. European Commission. Special Eurobarometer 472 - Sport and physical activity: Executive Summary. Brussels: European Union; 2018. Available from: https:/ec.europa.eu/commfrontoffice/publicopinion/index.cfm/Survey/ getSurveyDetail/instruments/SPECIAL/surveyKy/2164.

10. Shinogle MMJ. Physical activity: economic and policy factors. Cambridge: National Bureau of Economic Research; 2009.

11. Sport England. Go where women are: Insight on engaging women and girls in sport and exercise [Available from: https://www.sportengland.org/ media/10083/insight_go-where-women-are.pdf.

12. Department of Local Government Sport and Cultural Industries. Active living for all 2017-2019: a framework for physical activity in Western Australia. Leederville: Government of Western Australia; 2019.

13. White RL, Babic MJ, Parker PD, Lubans DR, Astell-Burt T, Lonsdale C Domain-specific physical activity and mental health: a meta-analysis. Am J Prev Med. 2017;52(5):653-66.

14. UN-Habitat. Sustainable Urban Development in Africa. Kenya: United Nations Human Settlements Programme; 2015.

15. Guthold R, Louazani SA, Riley LM, Cowan MJ, Bovet P, Damasceno A, et al. Physical activity in 22 African countries: results from the World Health Organization STEPwise approach to chronic disease risk factor surveillance. Am J Prev Med. 2011:41(1):52-60.

16. Longo-Mbenze B, Efini B, Ekwanzala, Ngoma V, Nahimana D, Fuele M, et al. Enquete sur les facteurs de risque des maladies non transmissibles a Kinshasa, capitale de la RD CONGO: Selon l'approche STEPS de I'OMS. Kinshasa: Ministère de la Santé Direction de la lutte contre la maladie; WHO; 2006.

17. Naby M. Guinée (Conakry et Basse Guinée) Enquête STEPS 2009: Note de synthèse World Health Organization; 2009.

18. Kenya Stepwise Survey for Non Communicable Diseases Risk Factors: KENKNBS-STEPS-2015-V0.1. Nairobi: Kenya National Bureau of Statistics; 2015. Available from: http://statistics.knbs.or.ke/nada/index.php/catalog/90 Accessed 20 Sept 2016.

19. Ministry of Health and Social Welfare. Liberia chronic disease risk factor surveillance. Liberia: Ministry of Health and Social Welfare, Republic of Liberia; 2011.

20. Bovet $P$, Viswanathan $B$, Louange $M$, Gedeon J. National Survey of Noncommunicable Diseases in Seychelles 2013-2014 (Seychelles Heart Study IV): main findings. Victoria, Republic of Seychelles: Unit of Prevention and Control of Cardiovascular Diseases (UPCCD), Public Health Authority, Ministry of Health; 2015.

21. Hird TR, Young EH, Pirie FJ, Riha J, Esterhuizen TM, O'Leary B, et al. Study profile: the Durban Diabetes Study (DDS): a platform for chronic disease research. Global health Epidemiol Genomics. 2016;1:e2.

22. Mayige M, Kagaruki G. Tanzania STEPS survey report. Tanzania: Ministry of Health and Social Welfare, National Institute for Medical Research, World Health Organization; 2013.

23. Ministry of Health Zanzibar. Zanzibar national NCD risk factor survey 2011. Zanzibar. Tanzania: Ministry of Health Zanzibar; 2012.

24. Agoudavi K. Rapport final de l'enquête STEPS Togo 2010. Togo: Ministère de la Santé; 2012.

25. Ministry of Health Republic of Uganda, World Health Organization, United Nations Development Programme, World Diabetes Foundation. Non-
Communicable Disease Risk Factor Baseline Survey: Uganda 2014 Report. Kampala: Ministry of Health; 2016. Available from: https:/www.who.int/ ncds/surveillance/steps/Uganda_2014_STEPS_Report.pdf.

26. WHO. WHO STEPS Surveillance Manual: The WHO STEPwise approach to noncommunicable disease risk factor surveillance. Geneva: WHO; 2017.

27. Division of Non-communicable Diseases. Kenya STEPwise Survey for non communicable diseases risk factors 2015 report. Nairobi, Kenya: Ministry of Health; 2015.

28. Prevention of Noncommunicable Diseases Department. Global Physical Activity Questionnaire (GPAQ) Analysis Guide. Geneva: WHO; 2002.

29. WHO. Global recommendations on physical activity for health. Geneva: World Health Organization; 2010.

30. Nyaga VN, Arbyn M, Aerts M. Metaprop: a Stata command to perform metaanalysis of binomial data. Archives of public health $=$ Archives belges de sante publique. 2014;72(1):39.

31. DerSimonian R, Laird N. Meta-analysis in clinical trials. Control Clin Trials. 1986;7(3):177-88.

32. Higgins JP, Thompson SG. Quantifying heterogeneity in a meta-analysis. Stat Med. 2002:21(11):1539-58

33. da Costa BR, Juni P. Systematic reviews and meta-analyses of randomized trials: principles and pitfalls. Eur Heart J. 2014;35(47):3336-45.

34. Harbord R, Higgins J. Meta-regression in Stata. Stata J. 2008;8(4):493-519.

35. UNDP. Human Development Reports: Human Development Data (19902015) New York, United States of America: United Nations Development Programme; 2016 [Available from: http://hdr.undp.org/en/data\#.

36. The World Bank. GDP per capita (current US\$): World Bank Group; 2017 [Available from: https://data.worldbank.org/indicator/NY.GDP.PCAP.CD.

37. The World Bank. Urban population growth (annual \%): World Bank Group; 2017 [Available from: https://data.worldbank.org/indicator/NY.GDP.PCAP.CD.

38. OGHIST - income groups: World Bank; [Available from: http://siteresources. worldbank.org/DATASTATISTICS/Resources/OGHIST.xls.

39. Groot HE, Muthuri SK. Comparison of domains of self-reported physical activity between Kenyan adult urban-slum dwellers and national estimates. Glob Health Action. 2017;10(1):1342350.

40. Msambichaka B, Abdul R, Abdulla S, Klatser P, Tanner M, Kaushik R, et al. A Cross-Sectional Examination of Physical Activity Levels and Their SocioDemographic Determinants in Southern Tanzania. Int J Environ Res Public health. 2018;15(6):1054.

41. Padrao P, Damasceno A, Silva-Matos C, Prista A, Lunet N. Physical activity patterns in Mozambique: urban/rural differences during epidemiological transition. Prev Med. 2012;55(5):444-9.

42. Sport and Recreation South Africa. Participation Patterns in Sport and Recreation Activities in South Africa: 2005 Survey. Pretoria: Department of Sports and Recreation; 2005. Available from: http://www.kzndsr.gov.za/ LinkClick.aspx?link=GIS/Participation+patterns+in+sport+and+recreation+ activities+in+SA.pdf.

43. Oguoma VM, Nwose EU, Skinner TC, Richards RS, Digban KA, Onyia IC. Association of physical activity with metabolic syndrome in a predominantly rural Nigerian population. Diabetes Metab Syndrome. 2016; 10(1):13-8.

44. Nigatu Haregu T, Khayeka-Wandabwa C, Ngomi N, Oti S, Egondi T, Kyobutungi C. Analysis of patterns of physical activity and sedentary behavior in an urban slum setting in Nairobi, Kenya. J Phys Act Health. 2016;13(8):830-7.

45. Peltzer K, Phaswana-Mafuya N. Physical inactivity and associated factors in older adults in South Africa. African J Phys Health Educ Recreation Dance (AJPHERD). 2012;18(3):447-60.

46. Mielke GI, Malta DC, de Sa GB, Reis RS, Hallal PC. Regional differences and correlates of leisure time physical activity in Brazil: results from the Brazilian National Health Survey-2013. Revista brasileira de epidemiologia $=$ Brazilian journal of epidemiology. 2015;18(Suppl 2):158-69.

47. Crespo CJ, Keteyian SJ, Heath GW, Sempos CT. Leisure-time physical activity among US adults: results from the third National Health and nutrition examination survey. JAMA Intern Med. 1996;156(1):93-8.

48. Lahti J, Holstila A, Lahelma E, Rahkonen O. Leisure-time physical activity and all-cause mortality. PLoS One. 2014;9(7):e101548.

49. WHO Regional Office for the Eastern Mediterranean. Promoting physical activity in the Eastern Mediterranean Region through a life course approach. Cairo: WHO; 2014.

50. Oyeyemi AL, Kolo SM, Oyeyemi AY, Omotara BA. Neighborhood environmental factors are related to health-enhancing physical activity and 
walking among community dwelling older adults in Nigeria. Physiother Theory Pract. 2019;35(3):288-97.

51. Malambo P, Kengne AP, Lambert EV, De Villiers A, Puoane T. Prevalence and socio-demographic correlates of physical activity levels among South African adults in Cape Town and Mount Frere communities in 2008-2009. Archives of public health $=$ Archives belges de sante publique. 2016;74:54.

52. Assah F, Mbanya JC, Ekelund U, Wareham N, Brage S. Patterns and correlates of objectively measured free-living physical activity in adults in rural and urban Cameroon. J Epidemiol Community Health. 2015;69(7):700-7.

53. Burton N, Turrell G, Oldenburg B. Participation in recreational physical activity: why do socioeconomic groups differ? Health Educ Behav. 2003; 30(2):225-44.

54. Kirk MA, Rhodes RE. Occupation correlates of adults' participation in leisuretime physical activity: a systematic review. Am J Prev Med. 2011;40(4):476-85.

55. Stalsberg R, Pedersen AV. Are Differences in Physical Activity across Socioeconomic Groups Associated with Choice of Physical Activity Variables to Report? Int J Environ Res Public Health. 2018;15(5):922.

56. Amusa LO, Toriola AL, Onyewadume IU, Dhaliwal HS. Perceived barriers to sport and recreation participation in Botswana. African J Phys Health Educ Recreation Dance. 2008;14(2):115-29.

57. Yoonyoung Cho DM, David Newhouse, David Robalino. Labor Markets in Low- and Middle-Income Countries: Trends and Implications for Social Protection and Labor Policies. The World Bank; 2012. Contract No.: 1207.

58. Whitfield GP, Carlson SA, Ussery EN, Fulton JE, Galuska DA, Petersen R. Trends in meeting physical activity guidelines among urban and rural dwelling adults - United States, 2008-2017. MMWR Morb Mortal Wkly Rep. 2019;68(23):513-8.

59. Bauman A, Allman-Farinelli M, Huxley R, James WP. Leisure-time physical activity alone may not be a sufficient public health approach to prevent obesity--a focus on China. Obesity Rev. 2008;9(Suppl 1):119-26.

60. Ng SW, Norton EC, Guilkey DK, Popkin BM. Estimation of a dynamic model of weight. Empir Econ. 2012;42(2):413-43.

61. Assah FK, Ekelund U, Brage S, Mbanya JC, Wareham NJ. Urbanization, physical activity, and metabolic health in sub-Saharan Africa. Diabetes Care. 2011;34(2):491-6.

62. Schrauwen P, Westerterp KR. The role of high-fat diets and physical activity in the regulation of body weight. Br J Nutr. 2000;84(4):417-27.

63. Abubakari AR, Lauder W, Agyemang C, Jones M, Kirk A, Bhopal RS, Prevalence and time trends in obesity among adult west African populations: a meta-analysis. Obesity Rev. 2008;9(4):297-311.

64. Yaya S, Ekholuenetale M, Bishwajit G. Differentials in prevalence and correlates of metabolic risk factors of non-communicable diseases among women in sub-Saharan Africa: evidence from 33 countries. BMC Public Health. 2018;18(1):1168.

65. Riley L, Guthold R, Cowan M, Savin S, Bhatti L, Armstrong T, et al. The World Health Organization STEPwise approach to noncommunicable disease riskfactor surveillance: methods, challenges, and opportunities. Am J Public Health. 2016;106(1):74-8.

66. Bull FC, Maslin TS, Armstrong T. Global physical activity questionnaire (GPAQ): nine country reliability and validity study. J Phys Act Health. 2009; 6(6):790-804.

67. Helmerhorst HHJ, Brage S, Warren J, Besson H, Ekelund U. A systematic review of reliability and objective criterion-related validity of physical activity questionnaires. Int J Behav Nutr Phys Act. 2012;9(1):103.

68. WHO. Assessing national capacity for the prevention and control of noncommunicable diseases: report of the 2017 global survey. Geneva: World Health Organization; 2018.

69. Sport England. THIS GIRL CAN DELIVERS RESULTS ONE YEAR ON UK2016 [Available from: https://www.sportengland.org/news-and-features/news/2 016/january/12/thisgirlcanbirthday/.

70. Netball Australia. Kau Mai Tonga [Available from: https://netball.com.au/kaumai-tonga/.

71. WHO. Tackling NCDs: 'best buys' and other recommended interventions for the prevention and control of noncommunicable diseases. Geneva: World Health Organization; 2017.

72. Malambo P, Kengne AP, Lambert EV, De Villers A, Puoane T. Association between perceived built environmental attributes and physical activity among adults in South Africa. BMC Public Health. 2017;17(1):213.

73. Sallis JF, Bowles HR, Bauman A, Ainsworth BE, Bull FC, Craig CL, et al. Neighborhood environments and physical activity among adults in 11 countries. Am J Prev Med. 2009;36(6):484-90.
74. Sallis JF, Floyd MF, Rodriguez DA, Saelens BE. Role of built environments in physical activity, obesity, and cardiovascular disease. Circulation. 2012;125(5): 729-37.

75. Coenen P, Huysmans MA, Holtermann A, Krause N, van Mechelen W, Straker LM, et al. Towards a better understanding of the 'physical activity paradox': the need for a research agenda. Br J Sports Med. 2020. https://doi.org/10. 1136/bjsports-2019-101343.

76. Barr AL, Young EH, Sandhu MS. Objective measurement of physical activity: improving the evidence base to address non-communicable diseases in Africa. BMJ Glob Health. 2018;3(5):e001044.

77. Coenen P, Huysmans MA, Holtermann A, Krause N, van Mechelen W, Straker LM, et al. Do highly physically active workers die early? A systematic review with meta-analysis of data from 193696 participants. Br J Sports Med. 2018; 52(20):1320-6.

78. Holtermann A, Marott JL, Gyntelberg F, Søgaard K, Suadicani P, Mortensen OS, et al. Occupational and leisure time physical activity: risk of all-cause mortality and myocardial infarction in the Copenhagen City Heart Study. A prospective cohort study. BMJ Open. 2012;2(1):e000556.

79. Ding D, Ramirez Varela A, Bauman AE, Ekelund U, Lee I-M, Heath G, et al. Towards better evidence-informed global action: lessons learnt from the lancet series and recent developments in physical activity and public health Br J Sports Med. 2020;54(8):462-8.

80. Juma PA, Mohamed SF, Matanje Mwagomba BL, Ndinda C, Mapa-Tassou C, Oluwasanu M, et al. Non-communicable disease prevention policy process in five African countries authors. BMC Public Health. 2018;18(Suppl 1):961.

\section{Publisher's Note}

Springer Nature remains neutral with regard to jurisdictional claims in published maps and institutional affiliations.
Ready to submit your research? Choose BMC and benefit from:

- fast, convenient online submission

- thorough peer review by experienced researchers in your field

- rapid publication on acceptance

- support for research data, including large and complex data types

- gold Open Access which fosters wider collaboration and increased citations

- maximum visibility for your research: over $100 \mathrm{M}$ website views per year

At BMC, research is always in progress.

Learn more biomedcentral.com/submissions 